\title{
Springing Forward
}

\author{
Brad Hokanson ${ }^{1}$
}

Published online: 20 January 2017

(C) Association for Educational Communications \& Technology 2017

It is that time of year for AECT where we, as an organization, are moving forward, on both the short term and long term. Our strategic plan is in active use, and our annual events continue in good health.

Presentation proposals for the Jacksonville convention are being reviewed, selected, and collected for the convention schedule. It is a process that will continue into the summer, and it requires great skill and the volunteer help of many in the organization. Division planners organize the process, recruit reviewers, and make the final decisions on acceptance, as each division asks its members to serve as proposal reviewers. Divisional leaders can be contacted to offer to help with reviewing; it is a great way to develop your skills and understanding of the field.

We can all look forward to attending the Jacksonville conference in November. We can be there as a participant as well as by involving yourself as a volunteer or presenter. Jacksonville is a wonderful city for the conference, and a great opportunity for all is the Early Bird registration, which will close in May.

The elections for this year have been completed and our newly elected officers are being more fully integrated into the governance of the organization. They will formally assume their positions in November at the annual conference in Jacksonville. And the search for next year's candidates is beginning. Candidates are being recruited, and nominations for the 2018 election for president should be sent to the

nominations committee, c/o AECT Past President Kay Persichitte, by email at kpersi@uwyo.edu.

One consistent aspect of AECT is its drive to constantly increase value for the membership through events and resources. This is particularly evident in the increasing number of publications for members, providing opportunities for authors and as references available to members. Also in that vein, a new AECT journal has been launched and will publish the first issue this year. The Journal of Formative Designs for Learning will host a symposium in conjunction with the Summer Leadership meetings in Jacksonville this July. Additionally, The 5th Handbook of Research in Educational Communications and Technology has received proposals for chapters and they are being selected for development. This newest version of the Handbook will be available to all of us as part of our member benefits. The other leading new AECT initiative (in conjunction with Springer), the major reference work, Learning Design, and Technology: An International Compendium of Theory, Research, Practice, and Policy, is moving forward, providing a dynamically updated and substantial resource for all members. And our other publications continue strong, with both TechTrends and Educational Technology, Research and Development being increasingly highly rated.

This remains your organization, and it seeks to be one that empowers you in your professional career. The opportunities that exist with AECT are open in many ways, and I invite your participation.

Brad Hokanson

brad@umn.edu

1 University of Minnesota College of Design, Minneapolis, MN 55455, USA 